Дейнега Валентина Николаевна

доктор экономических наук, профессор, профессор кафедры бухгалтерского учета, анализа и аудита

Кубанского государственного

технологического университета

Куракова Софья Викторовна

студентка Кубанского государственного технологического университета

\section{ВЛИЯНИЕ МЕТОДА ОЦЕНКИ РИСКА НЕОБНАРУЖЕНИЯ НА СНИЖЕНИЕ РИСКА СУЩЕСТВЕННОГО ИСКАЖЕНИЯ ФИНАНСОВОЙ ОТЧЕТНОСТИ}

Аннотация:

Статья посвящена оценке риска необнаружения как одного из элементов аудиторского риска. В процессе исследования на примере организации ООО "Строитель-2000» были применены несколько методик оценки аудиторского риска. Было выявлено, что наиболее эффективной методикой является вероятностный математический метод нечетких множеств. Данная методика была усовершенствована посредством разработки критериев отнесения факторов к различным классам риска (низкий, средний, высокий).

Ключевые слова:

аудиторский риск, риск необнаружения, косвенная модель, матричная модель, метод нечетких множеств, классы риска, критерии отнесения, факторы риска.
Deynega Valentina Nikolaevna

D.Phil. in Economics, Professor, Accounting, Analysis and Audit Department, Kuban State Technological University

Kurakova Sofia Viktorovna

Student,

Kuban State Technological University

\section{THE INFLUENCE OF DETECTION RISK-BASED APPROACH ON REDUCING RISK OF MATERIAL MISSTATEMENT AT THE FINANCIAL STATEMENTS}

Summary:

The article is devoted to detection risk assessment as one of the elements of audit risk. In the course of investigations by case study of Stroitel-2000 LLC, the authors applied several techniques for audit risk assessment. They revealed that the probability mathematics method of fuzzy sets is the most effective one. This method has been improved by working out criteria for referring risk classes (low, average, high).

Keywords: audit risk, detection risk, indirect model, matrix model, method of fuzzy sets, risk classes, criteria for referring, risk factors.

Выявление и оценка рисков при осуществлении аудита позволяет, во-первых, оценить степень вероятности вынесения аудитором неверного суждения, а во-вторых, позволяет разработать аудиторские процедуры таким образом, чтобы, с одной стороны, наилучшим образом способствовать достижению цели аудита и, с другой стороны, наиболее рациональным образом выделить ресурсы для проведения проверки. Аудиторский риск включает риск системы внутреннего контроля, риск системы бухгалтерского учета и риск того, что аудитор пропустит существенные нарушения и выразит ошибочное мнение об аудируемой финансовой отчетности. Выявлению и оценке риска посвятили свои исследования специалисты и ученые, причем все предлагаемые методики заслуживают внимания и могут быть использованы в практике аудита.

Аудит с 2017 г. проводится с применением международных стандартов аудита и в соответствии с МСA 200 «Общие цели независимого аудитора». Риск существенных искажений - это риск того, «что фринансовая отчетность была в существенной степени искажена до начала аудита» [1]. Задача аудитора состоит в том, чтобы оценить все риски, которые уже допущены, учесть их при разработке общей стратегии и нивелировать до приемлемого уровня.

Из-за несовершенства системы бухгалтерского учета всегда есть риск того, что данные учета подвержены искажению сами по себе, но в разной степени. Аудитор выделяет зоны наибольшего риска, где отдельные сальдо по счетам и связанные операции были подвержены большему количеству факторов, усугубляющих их достоверность. Риск несовершенства системы бухгалтерского учета - неотъемлемый - аудитор может оценить, но не может снизить. Несовершенства системы бухгалтерского учета выявляются и устраняются в результате контрольных мероприятий. Если система внутреннего контроля эффективна, то большинство несовершенств она выявит до составления финансовой отчетности. Но в случае низкой эффективности системы внутреннего контроля риск системы контроля возрастает. Как бы хорошо ни работала система внутреннего контроля, она может лишь уменьшить, но не полностью исключить риск системы котроля. 
Практика аудита в соответсвии с МСА показала, что, во-первых, неотъемлемый риск и риск внутреннего контроля не рассматриваются отдельно друг от друга, а выступают в виде объединенного понятия «риски существенных искажений», однако аудитор может выполнить отдельную оценку каждого вида рисков, если это предусмотрено методологией, выбранной в соответствии с профессиональным суждением; во-вторых, данные виды риска существуют еще до составления фринансовой отчетности. В процессе выполнения аудиторского задания аудитор выявляет и оценивает риски существенного искажения с тем, чтобы нейтрализовать их. На это направлен третий элемент составляющей аудиторского риска - риск необнаружения.

В модели аудиторского риска риск необнаружения находится в обратной зависимости от риска существенных искажений - чем выше выявленный аудитором риск существенного искажения, тем, соответственно, в большей степени должен быть снижен риск необнаружения путем эффективно разработанных аудиторских процедур. Таким образом, риск необнаружения находится под контролем аудитора и при проведении проверки может быть уменьшен в той степени, чтобы в совокупности с другими элементами аудиторского риска обеспечить приемлемый уровень аудиторского риска. Считается, что он не должен превышать $5 \%$, то есть 5 документов в совокупности могут содержать существенные искажения, и аудитор считает такие искажения несущественными в целом для отчетности. При определении риска необнаружения математическим методом используют косвенную модификацию известной формулы:

$$
\mathrm{AP}=\mathrm{HP} \times \mathrm{PCK} \times \mathrm{PH}[2],
$$

где АР - аудиторский риск,

HP - неотъемлемый риск,

РСК - риск системы контроля,

$\mathrm{PH}$ - риск необнаружения.

В данном случае аудитор, во-первых, посредством своего профессионального суждения находит значения неотъемлемого риска и риска внутреннего контроля, во-вторых, принимает значение аудиторского риска согласно общемировой практике как $5 \%$ и, далее, расчетным путем находит значение риска необнаружения [3].

Рассчитаем риск необнаружения посредством данной методики, применив косвенную модификацию формулы аудиторского риска на основе полученных в результате проведения тестов и опросов расчитанных значений неотъемлемого риска и риска необнаружения, которые для аудируемого нами ООО «Строитель-2000» составили 80,1 и 84,6 \%.

$$
\mathrm{PH}=0,05 /(0,801 \times 0,846) \text {. }
$$

Согласно расчету риска необнаружения по фрормуле косвенной модели, риск необнаружения составил 7,4 \%. В этом случае при разработке общей стратегии и плана проверки мы предусмотрели такие аудиторские процедуры, которые максимально направлены на выявление существенных искажений и позволят не пропустить существенные искажения более, чем это допустимо.

Следующая модель, которая применяется для расчета риска необнаружения, - матричная [4]. Алгоритм расчета является следующим: по вертикали откладываются уровни уже определенного неотъемлемого риска (высокий, средний и низкий), по горизонтали - соответствующие уровни риска контроля - и далее на пересечении этих уровней внутри пространства матрицы можно оценивать риск необнаружения в градации. Данная модель позволяет выявить объективную зависимость между тремя элементами аудиторского риска, а также обеспечить ее наглядное представление.

Рассмотрев данные модели оценки риска необнаружения, мы пришли к выводу, что эти методики позволяют оценить риск необнаружения только в его зависимости от остальных элементов аудиторского риска - неотъемлемого риска и риска внутреннего контроля. Они только показывают, каким должен быть риск необнаружения для проведения эффеективной аудиторской проверки, однако не позволяют объективно оценить его с учетом конкретных условий проведения данной аудиторской проверки и, следовательно, не позволяют выработать эффрективные мероприятия, направленные на его уменьшение.

Оценить риск необнаружения обособленно от других элементов трехфакторной модели аудиторского риска в его зависимости от факторов, оказывающих непосредственное влияние на эффективность аудиторской проверки с точки зрения работы аудитора, позволяет математическая вероятностная методика нечетких множеств. Пошаговое применение методики представлено в таблице 1 [5]. 
Таблица 1 - Применение метода нечетких множеств

\begin{tabular}{|c|c|c|c|c|}
\hline № & $\begin{array}{c}\text { Наименование } \\
\text { действия }\end{array}$ & Суть действия & Формула & Примечания \\
\hline 1 & $\begin{array}{l}\text { Введение } \\
\text { условных } \\
\text { обозначений }\end{array}$ & $\begin{array}{l}\mathrm{x}_{\mathrm{i}} \text { - анализируемый фактор } \\
\mathrm{N} \text { - количество факторов, } \\
\mathrm{I} \text { - текущий номер фактора } \\
\mathrm{r}_{\mathrm{i}} \text { - коэфффициент значимости каж- } \\
\text { дого фрактора }\end{array}$ & - & $\begin{array}{l}\text { Каждый анализируе- } \\
\text { мый фактор }\left(\mathrm{x}_{\mathrm{i}}\right) \text { может } \\
\text { иметь одну из трех } \\
\text { градаций риска - вы- } \\
\text { сокая, средняя, низкая }\end{array}$ \\
\hline \multirow[t]{2}{*}{2} & \multirow[t]{2}{*}{ Расчет значений $r_{i}$} & \multirow[t]{2}{*}{$\begin{array}{l}\text { Определяем значение коэффиици- } \\
\text { ента значимости каждого фактора }\end{array}$} & $r_{i}=1 / N$ & $\begin{array}{l}\text { Если все факторы } \\
\text { равнозначны }\end{array}$ \\
\hline & & & $r_{i}=r_{i} / \sum r_{i}$ & $\begin{array}{l}\text { Если фракторы нерав- } \\
\text { нозначны }\end{array}$ \\
\hline 3 & $\begin{array}{l}\text { Присвоение } \\
\text { текущего значения }\end{array}$ & $\begin{array}{l}\text { Каждому фрактору присваивается } \\
\text { его текущее значение аij, } 1 \text { или 0, в } \\
\text { зависимости от выбора аудитора }\end{array}$ & - & 然 \\
\hline 5 & $\begin{array}{l}\text { Ввод функции } \\
\text { принадлежности } \\
\text { риска }(\mathrm{g})\end{array}$ & $\begin{array}{l}\text { Вводится функция принадлежно- } \\
\text { сти g, областью определения ко- } \\
\text { торой является множество значе- } \\
\text { ний риска необнаружения, а мно- } \\
\text { жество значений - единичный ин- } \\
\text { тервал от } 0 \text { до } 1\end{array}$ & - & - \\
\hline \multirow[t]{3}{*}{6} & \multirow{3}{*}{$\begin{array}{l}\text { Классификация } \\
\text { текущих значений }\end{array}$} & \multirow{3}{*}{$\begin{array}{l}\text { Строим классификацию значений } \\
\text { g по разбиению множества на три } \\
\text { подмножества по классам }\end{array}$} & $0<\mathrm{g}<0,33$ & Низкий риск \\
\hline & & & $0,33<\mathrm{g}<0,6$ & Средний риск \\
\hline & & & $0,66<\mathrm{g}<1$ & Высокий риск \\
\hline 7 & $\begin{array}{l}\text { Определение } \\
\text { значения функции }\end{array}$ & $\begin{array}{l}\text { Определение значения функции } \\
\text { (риска необнаружения) }\end{array}$ & $\sum g_{j} \sum r_{i} \lambda_{i j}$ & $g_{j}=0,83-0,33(j-1)$ \\
\hline
\end{tabular}

Как уже было отмечено, данная методика, несмотря на сложность и многоступенчатость математических расчетов, имеет преимущество в том, что ее можно использовать не только для обособленной оценки неотъемлемого риска и риска внутреннего контроля, но и для обособленной оценки риска необнаружения (вне зависимости от трехфакторной мультипликативной модели аудиторского риска) - достаточно лишь составить набор факторов, оказывающих влияние на риск необнаружения, и осуществить с ними математические действия по данному методу.

Поскольку ключевым моментом при использовании данной методики является грамотный выбор факторов, оказывающих влияние на тот или иной элемент риска, а также их отнесение к классам «высокий», «средний», «низкий», в рамках усовершенствования данной методики применительно именно к риску необнаружения мы определили наиболее важные факторы, оказывающие влияние на риск необнаружения, и разработали критерии отнесения каждого фактора к своему классу (высокий, средний, низкий).

В модели выделяются следующие ключевые фракторы, определяющие риск необнаружения: профессионализм и квалификация аудитора ( $\left.\mathrm{x}_{1}\right)$; информированность аудитора об аудируемом лице (первичный или повторный аудит $\left(\mathrm{x}_{2}\right)$; планируемый вид источников аудиторских доказательств ( $\left.\mathrm{x}_{3}\right)$; необходимость привлечения экспертов $\left(\mathrm{x}_{4}\right)$; количество и качество разработанных внутрифрирменных стандартов (х5).

Факторы, определяющие риск необнаружения, мы классифицировали в соответствии с разработанными критериями отнесения каждого из этих фракторов к своему классу риска (таблица 2).

Таблица 2 - Классификация фракторов, влияющих на неотъемлемый риск

\begin{tabular}{|c|c|c|c|}
\hline Фактор & Низкий риск & Средний риск & Высокий риск \\
\hline $\mathrm{x}_{1}$ & $\begin{array}{l}\text { Опыт работы аудитором более } 5 \\
\text { лет }\end{array}$ & $\begin{array}{l}\text { Опыт работы аудитором } \\
\text { от } 1 \text { до } 5 \text { лет }\end{array}$ & $\begin{array}{l}\text { Опыт работы аудитором } \\
\text { менее } 1 \text { года }\end{array}$ \\
\hline $\mathrm{x}_{2}$ & $\begin{array}{l}\text { Повторный аудит данной органи- } \\
\text { зации }\end{array}$ & $\begin{array}{l}\text { Первичный аудит данной орга- } \\
\text { низации, но имеется опыт } \\
\text { аудита организаций данной от- } \\
\text { расли и похожей структуры }\end{array}$ & $\begin{array}{l}\text { Первичный аудит данной } \\
\text { организации и не име- } \\
\text { ется опыта аудита похо- } \\
\text { жих организаций }\end{array}$ \\
\hline$x_{3}$ & $\begin{array}{l}\text { Смешанные доказательства, } \\
\text { равное количество как внешних, } \\
\text { так и внутренних доказательств }\end{array}$ & $\begin{array}{l}\text { Смешанные доказательства } \\
\text { преобладанием внутренних }\end{array}$ & $\begin{array}{l}\text { Только внутренние дока- } \\
\text { зательства }\end{array}$ \\
\hline $\mathrm{X}_{4}$ & $\begin{array}{l}\text { Нет необходимости в привлече- } \\
\text { нии экспертов, так как отсутствует } \\
\text { специфика деятельности органи- } \\
\text { зации, непонятная аудитору }\end{array}$ & $\begin{array}{l}\text { Есть специфика деятельности, } \\
\text { непонятная аудитору, привлече- } \\
\text { ние экспертов планируется } \\
\text { только по значимым вопросам }\end{array}$ & $\begin{array}{l}\text { Есть специфика деятель- } \\
\text { ности, непонятная ауди- } \\
\text { тору, привлечение экс- } \\
\text { пертов не планируется }\end{array}$ \\
\hline$x_{5}$ & $\begin{array}{l}\text { Внутрифирменные стандарты } \\
\text { контроля качества разработаны, } \\
\text { соответствуют МСА, детализи- } \\
\text { рованы во всех аспектах }\end{array}$ & $\begin{array}{l}\text { Внутрифирменные стандарты } \\
\text { контроля качества разработаны, } \\
\text { соответствуют МСА, раскрыты } \\
\text { только главные положения }\end{array}$ & $\begin{array}{l}\text { Внутрифирменные стан- } \\
\text { дарты контроля качества } \\
\text { не разработаны }\end{array}$ \\
\hline
\end{tabular}


Рассмотрим применение данной методики на примере оценки риска необнаружения аудиторской проверки ООО «Строитель-2000». Перед проведением расчетов отметим, что фракторы являются равнозначными, следовательно, коэфффициент значимости для каждого составил 0,2.

Таблица 3 - Определение классов риска каждого фактора

\begin{tabular}{|c|c|c|c|c|c|c|}
\hline \multirow[t]{3}{*}{ Фактор } & \multicolumn{6}{|c|}{ Класс риска } \\
\hline & \multicolumn{2}{|l|}{ низкий } & \multicolumn{2}{|l|}{ средний } & \multicolumn{2}{|l|}{ высокий } \\
\hline & Описание & Оценка & Описание & Оценка & Описание & Оценка \\
\hline $\mathrm{X}_{1}$ & $\begin{array}{l}\text { Опыт работы аудито- } \\
\text { ром более } 5 \text { лет }\end{array}$ & 0 & $\begin{array}{l}\text { Опыт работы ауди- } \\
\text { тором от } 1 \text { до } 5 \text { лет }\end{array}$ & 0 & $\begin{array}{l}\text { Опыт работы } \\
\text { аудитором менее } \\
1 \text { года }\end{array}$ & 1 \\
\hline$x_{2}$ & $\begin{array}{l}\text { Повторный аудит дан- } \\
\text { ной организации }\end{array}$ & 0 & $\begin{array}{l}\text { Первичный аудит } \\
\text { данной организации, } \\
\text { но имеется опыт } \\
\text { аудита организаций } \\
\text { данной отрасли и по- } \\
\text { хожей структуры }\end{array}$ & 0 & $\begin{array}{l}\text { Первичный аудит } \\
\text { данной организа- } \\
\text { ции и не имеется } \\
\text { опыта аудита по- } \\
\text { хожих организа- } \\
\text { ций }\end{array}$ & 1 \\
\hline$x_{3}$ & $\begin{array}{l}\text { Смешанные доказа- } \\
\text { тельства, равное ко- } \\
\text { личество как внешних, } \\
\text { так и внутренних дока- } \\
\text { зательств }\end{array}$ & 0 & $\begin{array}{l}\text { Смешанные доказа- } \\
\text { тельства с преобла- } \\
\text { данием внутренних }\end{array}$ & 0 & $\begin{array}{l}\text { Только внутрен- } \\
\text { ние доказатель- } \\
\text { ства }\end{array}$ & 1 \\
\hline $\mathrm{X}_{4}$ & $\begin{array}{l}\text { Нет необходимости в } \\
\text { привлечении экспер- } \\
\text { тов, так как отсутствует } \\
\text { специфика деятельно- } \\
\text { сти организации, непо- } \\
\text { нятная аудитору }\end{array}$ & 0 & $\begin{array}{l}\text { Есть специфика дея- } \\
\text { тельности, непонят- } \\
\text { ная аудитору, привле- } \\
\text { чение экспертов пла- } \\
\text { нируется только по } \\
\text { значимым вопросам }\end{array}$ & & $\begin{array}{l}\text { Есть специфика } \\
\text { деятельности, } \\
\text { непонятная ауди- } \\
\text { тору, привлече- } \\
\text { ние экспертов не } \\
\text { планируется }\end{array}$ & 1 \\
\hline$x_{5}$ & $\begin{array}{l}\text { Внутрифирменные } \\
\text { стандарты контроля } \\
\text { качества разрабо- } \\
\text { таны, соответствуют } \\
\text { МСА, детализированы } \\
\text { во всех аспектах }\end{array}$ & 1 & $\begin{array}{l}\text { Внутрифирменные } \\
\text { стандарты контроля } \\
\text { качества разрабо- } \\
\text { таны, соответствуют } \\
\text { МСА, раскрыты } \\
\text { только главные по- } \\
\text { ложения }\end{array}$ & 0 & $\begin{array}{l}\text { Внутрифирмен- } \\
\text { ные стандарты } \\
\text { контроля каче- } \\
\text { ства не разрабо- } \\
\text { таны }\end{array}$ & 0 \\
\hline
\end{tabular}

Определим средние функции принадлежности для промежуточных расчетов: $\mathrm{g}_{1}$ - 0,83; $\mathrm{g}_{2}-0,5 ; \mathrm{g}_{3}-0,17$. Риск необнаружения согласно расчетам по математической вероятностной методике нечетких множеств для ООО «Строитель-2000» при тех же исходных данных, что и по трехфакторной модели, составил $31 \%$, в то время как согласно расчетам по трехфакторной модели он составил 7,4 \%. Мы наглядно увидели, что если полагаться на расчет по трехфакторной модели, то мы недооцениваем риск необнаружения, что может влиять на качество выполнения аудиторского задания. Риск необнаружения, рассчитанный по математической вероятностной методике нечетких множеств, свидетельствует о высоком риске необнаружения и, как следствие, о высоком аудиторском риске в целом при данной проверке. Это важно знать на стадии планирования с тем, чтобы предусмотреть все необходимые процедуры, в том числе дополнительные, и выявить существенные искажения в ходе проверки.

Проведенные расчеты показали, что применение методики нечетких множеств позволяет более точно оценить размер риска необнаружения на стадии планирования и обеспечить объективность и точность аудиторского мнения о достоверности аудируемой финансовой отчетности. Этому способствовали разработанные нами критерии отнесения факторов к классам риска, учитывающие факторы, непосредственно влияющие на качество выполнения аудиторского задания.

\section{Ссылки:}

1. William F., Messier Jr. An approach to learning risk-based auditing // Journal of Accounting Education. 2014. № 32. P. $276-287$.

2. Зайнулабидов А.А. Сущность аудиторского риска // Актуальные вопросы современной экономики в глобальном мире. 2016. № 5. С. 280-281.

3. Егорова И.С., Эредженова С.В. Оценка рисков в аудите // Учет, анализ, аудит. 2016. № 2. С. 95-105.

4. Сикорская А.И. Сравнительная характеристика экономических категорий коммерческий риск и аудиторский риск // Символ науки. 2016. № 8-1 (20). С. 141-145.

5. Кочинев Ю.Ю. Моделирование аудиторского риска при планировании аудита // Аудит и финансовый анализ. 2006. № 4. С. 127-130. 


\section{References:}

Egorova, IS \& Eredzhenova, SV 2016, 'Risk assessment in audit', Uchet, analiz, audit, no. 2, pp. 95-105, (in Russian).

Kochinev, YuYu 2006, 'Modeling the audit risk in audit planning', Audit i finansovyy analiz, no. 4, pp. 127-130, (in Russian).

Sikorskaya, Al 2016, 'Comparative characteristics of economic categories of commercial risk and audit risk', Simvol nauki, no. 8-1 (20), pp. 141-145, (in Russian).

William, F \& Messier, Jr 2014, 'An approach to learning risk-based auditing', Journal of Accounting Education, no. 32, pp. 276-287, https://doi.org/10.1016/j.jaccedu.2014.06.003.

Zaynulabidov, AA 2016, 'Essence of audit risk', Aktual'nyye voprosy sovremennoy ekonomiki v global'nom mire, no. 5, pp. 280-281, (in Russian). 